\title{
The Formation of Educational Programs in the Digital Environment
}

\author{
Tatiana A. Guzeva ${ }^{1 *}$, Alexander V. Baldin ${ }^{1}$, Pavel S. Perepelitsa ${ }^{1}$, Juliya B. Makarova $^{1}$, and \\ Tatiana $Y u$. Tsibizova ${ }^{1}$ \\ ${ }^{1}$ Bauman Moscow State Technical University, 2nd Baumanskaya str., 5/1, 105005, Moscow, Russia
}

\begin{abstract}
All the components of the university basic educational program and its formation in one system with the choice of the formation unit academic discipline are presented at the modeling level. A model, which is a unique system for the formation of educational programs and their components, is proposed. It allows to increase the mobility of all university departments that implement educational programs during licensing, accreditation and other examinations.
\end{abstract}

\section{Introduction}

In the digital economy it is necessary to change the approach to education management. The educational process should be not only flexible, but also mobile in accordance with modern requirements during its' formation $[1,2,3]$. Currently, all educational organizations are developing regulations or local normative acts that govern the design process of educational programs $[4,5]$.

The design of educational programs is necessary for solving two groups of problems in universities:

1) maintaining the quality of education at a high level for the training of highly qualified personnel;

2) ensuring accreditation and licensing indicators at the highest quality level.

Most of the works $[6,7,8]$ discuss the theoretical and methodological foundations of training highly qualified personnel for the modern Russian economy, related to the formation of the learning process as an electronic open socio-pedagogical system. The issues of educational structures integration in the higher education system are considered, innovative processes, which reflect the features of the formation of the higher education system programs, including ones with the advanced character, practice-oriented and differentiated approaches, are determined $[9,10]$. Some works are devoted to the design of educational programs in general, but does not affect the methods of their formation in an automated digital environment [11]. However, it is currently impossible to imagine the sustainable development of a modern university without automation of key areas of higher educational institution activity [12].

The introduction of automated information systems for the educational process controlling in Russia became widespread with the introduction of federal state educational

* Corresponding author: gta29@bmstu.ru 
standards of the 3rd generation. The software developers in this area offer their own methods and means of the educational process controlling. A review and selection of the most effective and appropriate education controlling systems for a particular university is presented in $[13,14]$.

The study of the possibilities of using automated systems specifically for the educational programs design is the main difference of the proposed research from previous ones, presented in works.

The project methodological basis consists from pedagogical and scientific principles and approaches: systemic, active, competency-based, personality-oriented approaches in the carrying out educational activities and the implementation of the educational process; principles of continuity, variability, integration in the MEP formation and design.

The development of a modern university and the automation of educational activities are inextricably linked with each other in the digital era [15]. A wide variety and complex dynamically changing connections of business processes implemented in higher education institutions determine the functional and structural features of the university automation systems [16]. On the one hand, each department solves its characteristic tasks. This requires the creation of specialized software products for these departments. On the other hand, it is necessary to realize the interaction of various subsystems among themselves. A logical solution to this problem is the introduction of a unified automated university information system with one database for storing all information, which will provide the necessary flexibility and efficient exchange of information between subsystems thanks to the modular architecture. The actualization and implementation of such an integrated system makes it possible to increase the effectiveness of university management as a whole significantly.

\section{Methods and solutions}

There is a number of additional difficulties associated with the volume of generated documents while designing educational programs in large universities, such as BMSTU. Nowadays BMSTU implements about 500 educational programs, including 10,000 programs of disciplines and practices. It isn't possible to obtain high-quality educational programs with such a volume of data without the use of modern digital technologies.

Thus, the goal has been set: to develop own model for the design of educational programs at BMSTU for increasing the efficiency of educational process management and, as a result, improving the quality of education through the use of modern digital technologies [17].

The developed model for educational programs designing allows to form the components of educational programs and their participants in one system, while ensuring the flexibility of educational trajectories, mobility of all the university departments and improving the quality of training [18].

The control of the educational program through a unique system of the formation of all its components allows to calculate the effectiveness of programs at all stages of implementation, identifying unprofitable elements at early stages with the possibility of their subsequent updating, and conducting multi-stage expert quality control of the prepared documents $[19,20]$.

BMSTU is currently implementing 478 educational programs at all levels of higher education (Fig. 1). 


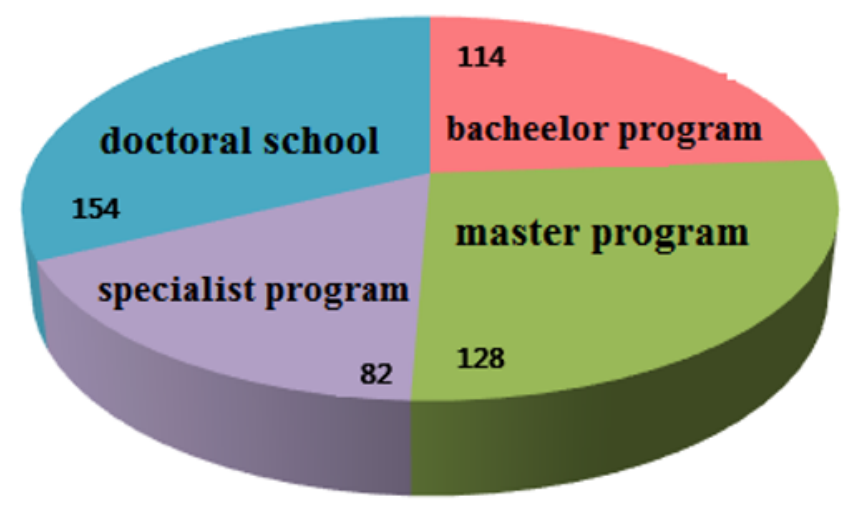

Fig. 1. The number of MEPs by training levels.

The main educational program (MEP) is a complex of the main characteristics of education (volume, content, planned results), organizational and pedagogical conditions, certification forms, which are presented in the form of a curriculum, calendar curriculum, work programs of educational subjects, courses, disciplines (modules), other components, as well as assessment and methodological materials (Part 9 of Article 2 of the Federal Law "On Education in the Russian Federation" dated by December 29, 2012 No. 273-FL). The organization and implementation of educational activities for educational programs are enshrined in the documents of the Ministry of Science and Higher Education of the Russian Federation.

Schematically, the components of MEP are shown in fig. 2.

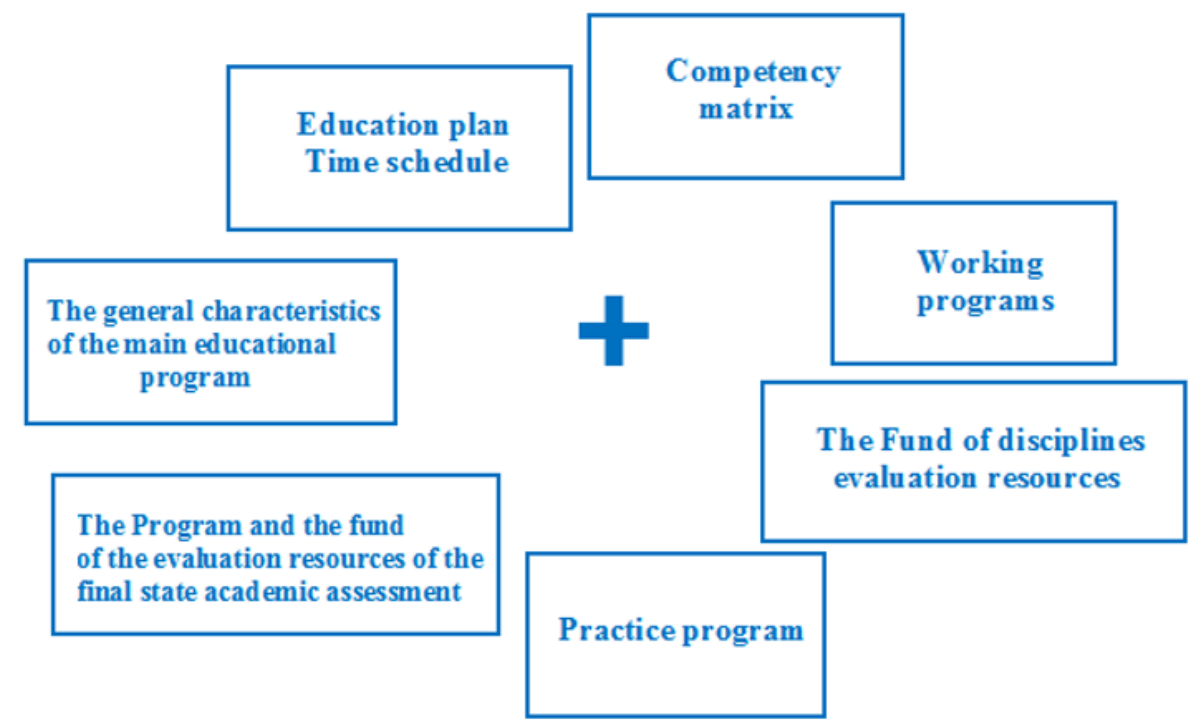

Fig. 2. The MEP main components.

The educational program is a voluminous multi-page document (Fig. 3). 


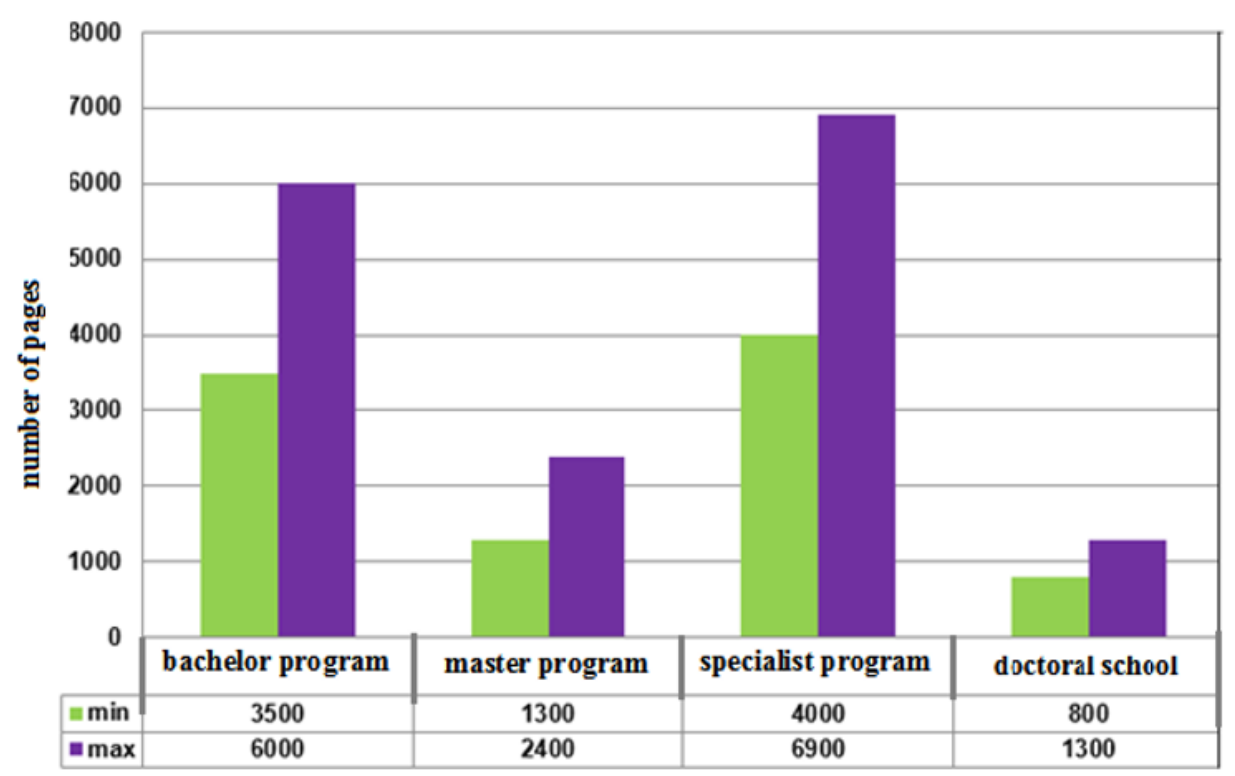

Fig. 3. MEP volume by higher education level.

And the requirements for the MEP implementation, which are prescribed in educational standards, supply the number of necessary documents for licensing and accreditation checks (Fig. 4).

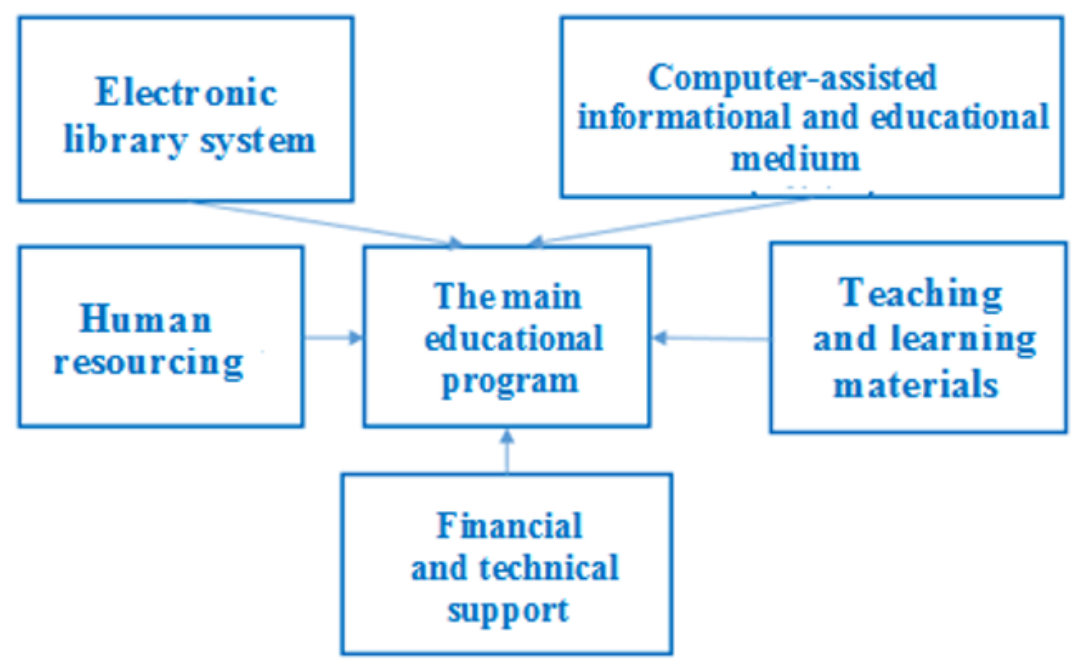

Fig. 4. List of requirements for the MEP implementation.

\section{Results and discussion}

The first stage of modeling begins with filling out the "Library of Disciplines". It is created for each department. The flexibility of the system allows one to enter parameters and control them, in accordance with the standards approved by orders on the organization of 
students extracurricular independent work and point-rating system, as well as to improve the quantitative data of disciplines and practices to improve the training quality. The interface of each individual discipline or practice program includes data on their methodological support, forming a list of basic literature through the University electronic library system.

In addition, the programs of disciplines and practices can be formed as a document in the subsystem "Library of Disciplines" and, before being approved and downloaded for students to access, undergo multi-stage control: according to formal parameters - the presence of all necessary sections; in content - the conclusion of the expert-specialist. All this is held in electronic form and is controlled in the "Electronic University" system. Thus, the generated documents quality is achieved.

The subsystem "Curriculum" allows one to see the library of disciplines of all departments and to form curricula on their basis and obtain annual curricula automatically from them.

The subsystem "Standards" is the controlling element in the preparation of curricula in accordance with the requirements of educational standards. This subsystem is multilevel and includes data from federal state educational standards (FSES) of all generations, including self-established educational standards (SEES).

The system of calculating the training load of lecturers and the formation of staffing has been rethought. The subsystem "Calculation of the training load" automatically loads data from the curriculum, load standards, contingent and the curriculum additional module for the course's formation. One can vary the number of positions by changing the parameters of the discipline, load standards and the volume of course's training. The department training load consists of budgetary, extra-budgetary components, as well as the load associated with the training of foreign students. Additional modules of this subsystem allow one to create the department staffing and individual plans of lecturers.

Since a unified identification system has been introduced in the library of disciplines, this allows to improve and optimize the preparation of class schedules in the subsystem "Class schedule of the educational process" in many ways.

Thus, starting from a specific discipline, basic educational programs, including curricula, work programs of disciplines, annual curricula, are formed and the educational programs staffing and the schedule for conducting training sessions are determined from it. All these components are formed in a digital environment using the developed automated system.

\section{Conclusion}

An original model of the basic university educational programs design on the basis of a library of disciplines with multi-level quality control has been proposed.

The implementation of the developed design model of the basic educational programs for the individual components of the educational process using the information system "Electronic University" has been presented.

As a result of the work, a powerful tool has been obtained, which is adapted to the specifics of the educational processes design, including:

- automation of obtaining key educational processes, as a unique and innovative solution that allows to increase the level of educational process control quality;

- integration of all the data of the educational environment, contributing to the creation of a universal platform for communication of all its participants, in one place;

- prompt data accessing in various types of presentation;

- increasing the processes transparency; 
- acceleration of managerial decision making;

- reporting on accreditation and licensing checks online;

- implementation of an integrated approach to control the organization of the educational process, the formation of competencies and the construction of an individual trajectory by students due to the multifunctionality and mobility of the system.

\section{References}

1. A.A. Aleksandrov, K. Fang, A.V. Proletarsky, K.A. Neusypin, Conception complex continuous education with innovative information technologies, Proceedings of 2nd International Conference on Education and Education Management (EEM 2012), pp. 374-378 (2012). Retrieved from www.scopus.com.

2. V.G. Brekalov, N.Y. Terekhova, A.I. Klenin, The information model for choosing theeducational process development strategy, European Social Science Journal, No. 93 (36), pp. 61-68 ( 2013).

3. A.A. Aleksandrov, K.A. Neusipin, A.V. Proletarsky, K. Fang, Innovation development trends of modern management systems of educational organizations, Proceeding of 2012 International Conference on Information Management, Innovation Management and Industrial Engineering, ICIII 2012, 3, pp. 187-189 (2012). Retrieved from www.scopus.com.

4. O.V. Spiridonov, O.K. Opolonskaya, T.A. Guzeva, The combination of educational and professional standards: problems and solutions, All materials, Encyclopedic reference book, No. 5, pp. 74-79 (2016).

5. P. Svoboda, Digital technology as a significant support for the teaching process, Advances in Intelligent Systems and Computing, 1018, pp. 383-389 (2020). Retrieved from www.scopus.com.

6. M.G. Sergeeva, Y.A. Chighovskaya-Nazarova, S.V. Dmitrichenkova, S.Y. Papirovskaya, V. A. Chauzova, I. S. Andryushchenko, Effectiveness verification of the application of imitation methods of education in the training of a specialist, Espacios, 39(38), 11 (2018). Retrieved from www.scopus.com.

7. L.V. Gaidarenko, O.A. Isabekova, P.A. Kapyrin, N.A. Meshkov, A.E. Popovich, Innovation development concept of the Russian educational complex in the conditions of information society, Astra Salvensis, 6, pp. 723-734 (2018). Retrieved from www.scopus.com.

8. A.A. Larionova, N.A. Zaitseva, Y.F. Anoshina, L.V. Gaidarenko, V.M. Ostroukhov, The modern paradigm of transforming the vocational education system, Astra Salvensis, 6, pp. 436-448 (2018). Retrieved from www.scopus.com.

9. V.M. Dudin, N.V. Lyasnikov, M.Y. Veselovsky, V.D. Sekerin, V.D. Aleksakhina, The problem of forecasting and modelling of the innovative development of socialeconomic systems and structures, Life Science Journal, 11(8), pp. 549-552 (2014). Retrieved from www.scopus.com.

10. M.S. Donovan, Generating improvement through research and development in education systems, Science, 340(6130), pp. 317-319 (2013). Retrieved from www.scopus.com.

11. E.V. Smirnova, A.A. Dobrjkov, A.P. Karpenko, V.V. Syuzev, Mentally structured educational technology and engineers preparation quality management, 
Communications in Computer and Information Science, 754, pp. 119-132 (2017). Retrieved from www.scopus.com.

12. S.N. Sailin, N.A. Mahmor, Improving student teachers' digital pedagogy through meaningful learning activities, Malaysian Journal of Learning and Instruction, 15(2), pp. 143-173 (2018). Retrieved from www.scopus.com.

13. E.B. Khvetskovich, M. S. Mazurik, Automated information systems for managing the educational process of a university: a practical study, Human science: humanitarian studies, No 2 (8), pp. 138-149 (2011).

14. M.O. Tubekov, A.S. Kasymbekov, Automated information system "University", Young scientist, No. 11, pp. 47-51 (2017).

15. I. Kmecová, Digitization, Digital Technology, and Importance of Digital Technology in Teaching, Lecture Notes in Networks and Systems, 84, pp. 526-537. Retrieved from www.scopus.com.

16. M.F. Alcibar, A. Monroy, M. Jiménez Impact and use of information and communication technologies in higher education, Informacion Tecnologica, 29(5), pp. 101-110 (2018). Retrieved from www.scopus.com.

17. T.I. Ageeva, A.V. Baldin, V.A. Baryshnikov \& others, Information management system of BMSTU "Electronic University: concept and implementation, Ed. I.B. Fedorova. M.: Publishing House of BMSTU, p. 376 (2009).

18. A.V. Baldin, T.A. Guzeva, T.Y. Tsibizova, Development of a digital environment for the design of educational programs, Twelfth All-Russian Conference of Young Scientists and Specialists (with international participation) "The Future of Russian Engineering": collection of reports, pp. 918-921 (2019).

19. N.A. Serdyukova, V.I. Serdyukov, S.S. Neustroev, S.I. Shishkina, Assessing the reliability of automated knowledge control results, Paper presented at the IEEE Global Engineering Education Conference, EDUCON, pp. 1425-1428 (2019). DOI:10.1109/EDUCON.2019.8725173 Retrieved from www.scopus.com.

20. M.G. Sergeeva, N.N. Bedenko, T.Y. Tsibizova, M.S. Mohammad Anwar, T.G. Stanchuliak, Organisational economic mechanism of managing the growth of higher education services quality, Espacios, vol. 39 (\# 21), 10 (2018). Retrieved from www.scopus.com. 